\title{
Influence of the Solution-Treatment Temperature and Short Aging Times on The Electrochemical Corrosion Behaviour of Uns S32520 Super Duplex Stainless Steel
}

\author{
Livio de Carvalho Valeriano ${ }^{a}$, Edmilson Otoni Correa ${ }^{a *}{ }^{(}$, Neide Aparecida Mariano ${ }^{b}(\mathbb{D}$, \\ Alain Laurent Marie Robinc, Maria A. G. Tommaselli Chuba Machado ${ }^{d}$ \\ ${ }^{a}$ Universidade Federal de Itajubá, Itajubá, MG, Brasil. \\ ${ }^{b}$ Universidade Federal de Alfenas, Poços de Caldas, MG, Brasil. \\ ${ }^{c}$ Escola de Engenharia de Lorena, Universidade de São Paulo, Lorena, SP, Brasil. \\ ${ }^{d}$ Faculdade de Engenharia, Rodovia Dourados, Universidade Federal da Grande Dourados, \\ Dourados, MS, Brasil.
}

Received: November 29, 2018; Accepted: May 09, 2019

\begin{abstract}
Sigma phase leads to deterioration of corrosion resistance of super duplex stainless steels (SDSS) and its volume fraction increases as the time which the materials is exposed in determined temperature increases. In the present study, the effect of the short aging time on the formation of the sigma phase and on the corrosion behavior of UNS S32520 SDSS at 3.5\% sodium chloride solution was evaluated using microstructural characterization, linear potentiodynamic polarization curve and electrochemical impedance spectroscopy. The results indicated that the SDSS sample solution-treated at $1150^{\circ} \mathrm{C}$ and aged at $850^{\circ} \mathrm{C}$ for 5 min may improve the corrosion resistance in comparison with the as-received and solution-treated conditions, due to the better partition of the elements $\mathrm{Cr}$, Mo and dissolution of certain amount of sigma phase in the microstructure. However, results also showed that when SDSS solution-treated at $1150^{\circ} \mathrm{C}$ is aged at $850^{\circ} \mathrm{C}$ with the aging time slightly superior $(10 \mathrm{~min})$, the precipitation of sigma phase increases leading to a rapid deterioration of the corrosion resistance of the material.
\end{abstract}

Keywords: Super duplex stainless steel, electrochemical impedance spectroscopy, potentiodynamic polarization, sigma phase.

\section{Introduction}

Super duplex stainless steels (SDSS) are basically Fe-Cr-Ni-Mo-N system alloys presenting a microstructure of approximately $50 \mathrm{vol} \%$ ferrite $(\alpha)$ and $50 \mathrm{vol} \%$ austenite $(\gamma)$, and their high $\mathrm{Cr}$ and Mo content allow the combination of excellent mechanical properties and high corrosion resistance, mainly in environments containing halogen family ions, specially the chloride ion ${ }^{1-4}$.

The combination of these properties make SDSS extremely interesting for use in the oil, chemical, offshore petroleum, and electric power industries, which require materials with high strength and toughness combined with high corrosion and stress corrosion resistance ${ }^{5,6}$.

Super duplex duplex stainless steels are useful as wrought alloys, castings and weld, and have replaced successfully austenitic stainless steels in many severe operational applications where higher pitting, crevice and stress corrosion resistance in high temperatures are mandatory requirements, such as seamless tubes, valves and wellheads.

However, despite their superior mechanical and corrosion resistance properties, they are susceptible to precipitation of intermetallic phases as a consequence of the thermodynamic instability of the ferrite in the temperature range from 300 to $1050^{\circ} \mathrm{C}^{7}$.
The formation of these intermetallic phases, such as the sigma $(\sigma)$ phase in SDSS is totally undesirable since it causes the depletion of $\mathrm{Cr}$ and $\mathrm{Mo}$, in the regions adjacent to the matrix due to their consumption in solid solution, during the alloying process, welding process, heat treatment or during material aging, which results in the reduction of the corrosion resistance and mechanical properties ${ }^{7-9}$.

This phase is basically Fe-Cr-Mo intermetallic compound and it is formed in the austenite/ferrite interface by nucleation and grown processes. Depending on its amount in the SDSS, the corrosion resistance decreases considerably whereas the hardness and mechanical strength increase $\mathrm{e}^{10-13}$.

Considering that the ferrite and austenite phases have different chemical compositions, the 1:1 proportion of austenite and ferrite phases in a SDSS is obtained especially by the austenite stabilizing elements (carbon, nickel, nitrogen) and ferrite stabilizing elements (chromium, molybdenum) ${ }^{11-13}$. It is well established that the partition of the elements between austenite and ferrite changes as the time of exposition of the SDSS at determined temperature during service and/or thermal processing increases, leading to the precipitation of sigma phase. However, it is difficult to determine, for a specific service temperature, the exposition time which 
the sigma phase starts to precipitate massively and affects significantly the corrosion resistance, mainly the pitting resistance $^{13}$. Once this exposition time is known, it is possible to avoid the excessive formation of sigma phase during thermal processing, such as hot rolling and welding.

Concerning to pitting corrosion potential, it is influenced by the composition of the environment, the aggressive ion concentration, the temperature, the alloy composition, and the presence of sigma phase ${ }^{11}$.

The objective of this work therefore was to evaluate the influence of the solution-treatment and short aging times on the sigma phase $(\sigma)$ precipitation and on the electrochemical corrosion behavior of UNS S32520SDSS taking in account the thermal cycles adopted, which are similar to those observed during thermal processing of these steels to fabricate several components of petrochemical industries.

\section{Materials and Methods}

The material studied was UNS S32520 SDSS and Table 1 shows the nominal chemical composition.

The samples were solution-treated at $1150^{\circ} \mathrm{C}$ for $30 \mathrm{~min}$, under nitrogen atmosphere, and cooled in water. After that, aging treatments were performed at $850^{\circ} \mathrm{C}$ for 5 and $10 \mathrm{~min}$., followed by cooling in air.

Samples used for microstructural characterization and electrochemical tests had their tested surfaces polished using $1 \mu \mathrm{m}$ diamond abrasive and then rinsed with ethyl alcohol. The samples were analyzed by scanning electron microscopy (SEM) and the semi quantitative microanalysis of the phases was obtained by energy dispersive spectrometer (EDS), after electrolytic etching in $10 \%$ potassium hydroxide $(\mathrm{KOH})$ aqueous solution for $30 \mathrm{~s}$. The X-ray diffractometry (XRD) with $\mathrm{Cu} \mathrm{Ka}$ radiation was also performed to determine the phases present. The microhardness (HV) test was performed with a load of $4.9 \mathrm{~N}$ and printing time of 10 seconds.

Corrosion behavior was evaluated by linear potentiodynamic polarization method using a connected to a typical electrochemical cell with a saturated calomel electrode (SCE) used as a reference electrode, a platinum plate employed as counter-electrode and the working electrode made from the steel studied. The potentiodynamic curves were measured at a potential scan rate of $1 \mathrm{mV} / \mathrm{s}$ in the range from $-0.5 \mathrm{~V}$, in relation to the corrosion potential, to $+1.5 \mathrm{~V} / \mathrm{SCE}$. The electrolyte used was $3.5 \%$ sodium chloride solution at $25^{\circ} \mathrm{C}$.

Electrochemical impedance spectroscopy (EIS) measurements were carried out using a frequency response analyser coupled to a potentiostat. The EIS measurements were performed at the open-circuit potential (OCP). The amplitude of the sinusoidal potential signal was $10 \mathrm{mV}$ and investigated frequency was from $100 \mathrm{KHz}$ to $10 \mathrm{mHz}$, with an acquisition rate of 10 points per decade. The EIS measurements were obtained prior to the cyclic polarization tests.

\section{Results and Discussions}

The micrograph of UNS S32520 SDSS in as received are shown in Figure 1a. Note the austenite (light phase) is in the form of elongated islands, and in alternate regions of refined and acicular structures, dispersed in the ferritic matrix (dark phase). Micrograph of the UNS S32520 SDSS solution-treated at a temperature of $1150^{\circ} \mathrm{C}$ for $30 \mathrm{~min}$ and cooled to water, are shown in Figure 1b, note that the austenite is in the form of lamella islands, distributed in the ferritic matrix. The formation of the lamellar microstructure is induced by the fact that the ferrite/austenite interface energy is lower than the energies of the ferrite and austenite grain contours.

Figure 1c e 1d shows micrographs of UNS S32520 SDSS samples aged at $850^{\circ} \mathrm{C}$ for $5 \mathrm{~min}$. and $10 \mathrm{~min}$., respectively. In the micrographs of the both samples aged, precipitation of sigma phase can be observed in the interface of ferrite and austenite grains. It can also be observed that the volume fraction of this phase increase as the aging time increases from 5 to $10 \mathrm{~min}$.

Through the X-ray analysis (XRD), Figure 2a, it can be observed the presence of only the ferrite phase $(\alpha)$ and austenite phase $(\gamma)$, for the as received. Although the Figure $1 \mathrm{~b}$ did not reveal the presence of sigma phase, XRD results of the sample in the solution-treated condition showed that this phase was also present in volume fraction considerable and superior to that observed in the samples aged for $5 \mathrm{~min}$ (Figs. 2b and 2c).

Although the Figure 1b did not reveal the presence of sigma phase, XRD results of the sample in the solutiontreated condition showed that this phase was also present in volume fraction considerable and superior to that observed in the samples aged for $5 \mathrm{~min}$ (Figure $2 \mathrm{~b}$ and $2 \mathrm{c}$ ).

It is possible to infer that aging times of less than $10 \mathrm{~min}$ can produce a better partition of the $\mathrm{Cr}$ and Mo elements and a significant dissolution of the sigma phase present in the solution- treated condition, this fact may also have contributed to the displacement of the peak of (420) $2 \theta$ (degree) by comparing Figures $2 \mathrm{~b}$ and $2 \mathrm{c}$. On the other hand, $\mathrm{XRD}$ results indicate that when the aging time is slightly increased for $10 \mathrm{~min}$, it occurs a massive re-precipitation of the sigma phase (Figure 1d and Figure 2d).

It was observed by quantitative stereology that in the condition as received the volumetric fraction of the ferrite and autenite phases were $59.83 \pm 2.865 \%$ and $39.89 \pm 2.865 \%$, respectively. Increasing the time in the thermal treatment of

Table 1. Nominal chemical composition (in wt \%) of the SDSS UNS S32520

\begin{tabular}{ccccccccccccc}
\hline $\mathbf{C}$ & $\mathbf{S i}$ & $\mathbf{M n}$ & $\mathbf{S}$ & $\mathbf{P}$ & $\mathbf{C r}$ & $\mathbf{N i}$ & $\mathbf{M o}$ & $\mathbf{N}$ & $\mathbf{C u}$ & $\mathbf{F e}$ \\
\hline 0.02 & 0.29 & 0.87 & 0.001 & 0.046 & 24.90 & 6.50 & 4.04 & 0.228 & 1.39 & Bal. \\
\hline
\end{tabular}




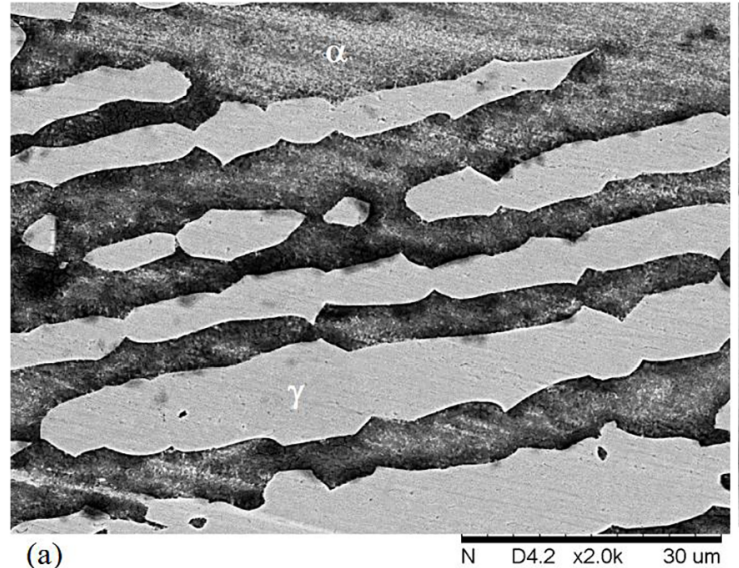

(a)

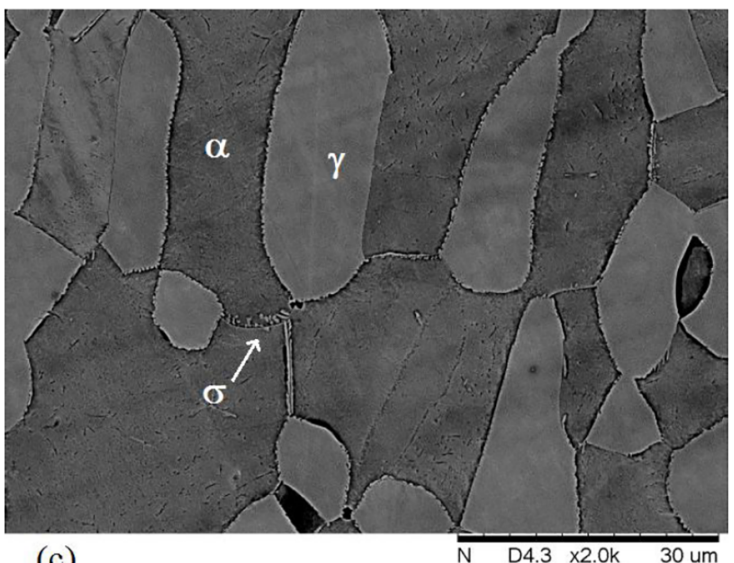

(c)
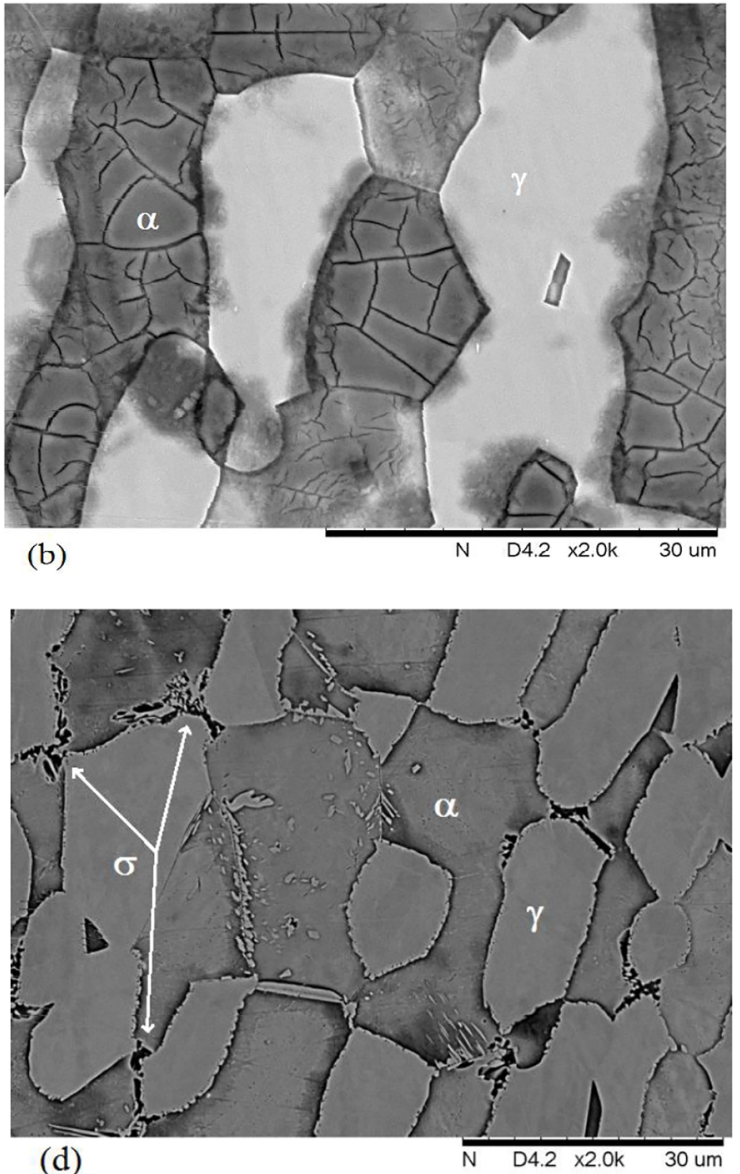

Figure 1. SEM of UNS S32520 super duplex stainless steel. (a) as-received; (b) solution-treated at $1150^{\circ} \mathrm{C}$; (c) solution-treated at $1150^{\circ} \mathrm{C}$ and aged at $850^{\circ} \mathrm{C}$ for $5 \mathrm{~min}$., (d) solution-treated at $1150^{\circ} \mathrm{C}$ and aged at $850^{\circ} \mathrm{C}$ for $10 \mathrm{~min}$

aging favors the precipitation of secondary phases, mainly the sigma phase, and the volumetric fraction of the ferrite phase decreases with increasing aging time, due to the eutectoid reaction $(\alpha \rightarrow \gamma 2+\sigma)^{14}$. And the volumetric fractions of the secondary phases precipitated during the heat treatment of aging of $5 \mathrm{~min}$ and $10 \mathrm{~min}$ were $5.76 \pm 2.78 \%$ and $9.71 \pm$ $2.20 \%$, respectively.

Table 2 shows the microhardness values of the SDSS and note that is not affected by the presence of the sigma phase, the treated solution was aged for $5 \mathrm{~min}$ and $10 \mathrm{~min}$, the precipitation of the secondary phases was insufficient to affect the microhardness.

Table 3 presents the open circuit potentials after 3 -hour immersion and it is observed that there was no significant variation of them in the samples indicating a passive behavior among the studied conditions.

Linear potentiodynamic polarization curves are presented in Figure 3 and Table 4 presents the electrochemical parameters Ecorr (corrosion potential), Icorr (corrosion current density), Epit (pitting potential) and Ipass (passive current density). Note that all the curves are similar, displaying some minor differences only in the regions of high potential.
The polarization curves present two passive regions, indicated in Figure 3 (region A and B), this behavior is due to the duplex microstructure, composed of ferritic and austenitic phases. The first passive region (region A) is associated with the passivation of the ferrite phase and the second passive region (region B) is associated with the austenite phase ${ }^{15,16}$.

The corrosion potentials of these polarization curves are more negative than the values determined by the open circuit potentials measurement, this is shown by Table 3 and Table 4. This difference can be attributed mainly to the incomplete stabilization of the passive layer formed on the surface of the samples and the realization of cathodic polarization before reaching full stabilization of the open circuit potential.

The corrosion current densities determined from the polarization curves by the extrapolation method are in the order of $10^{-7} \mathrm{~A} . \mathrm{cm}^{-2}$ for the tested conditions. These values indicate high corrosion resistance of SDSS in $3.5 \% \mathrm{NaCl}$ solution. It may be observed in Figure 3 that the steel passivity breakdown for all the tested conditions occurs at approximately $+0.900 \mathrm{~V} / \mathrm{SCE}$, as there is an increase in current density. 

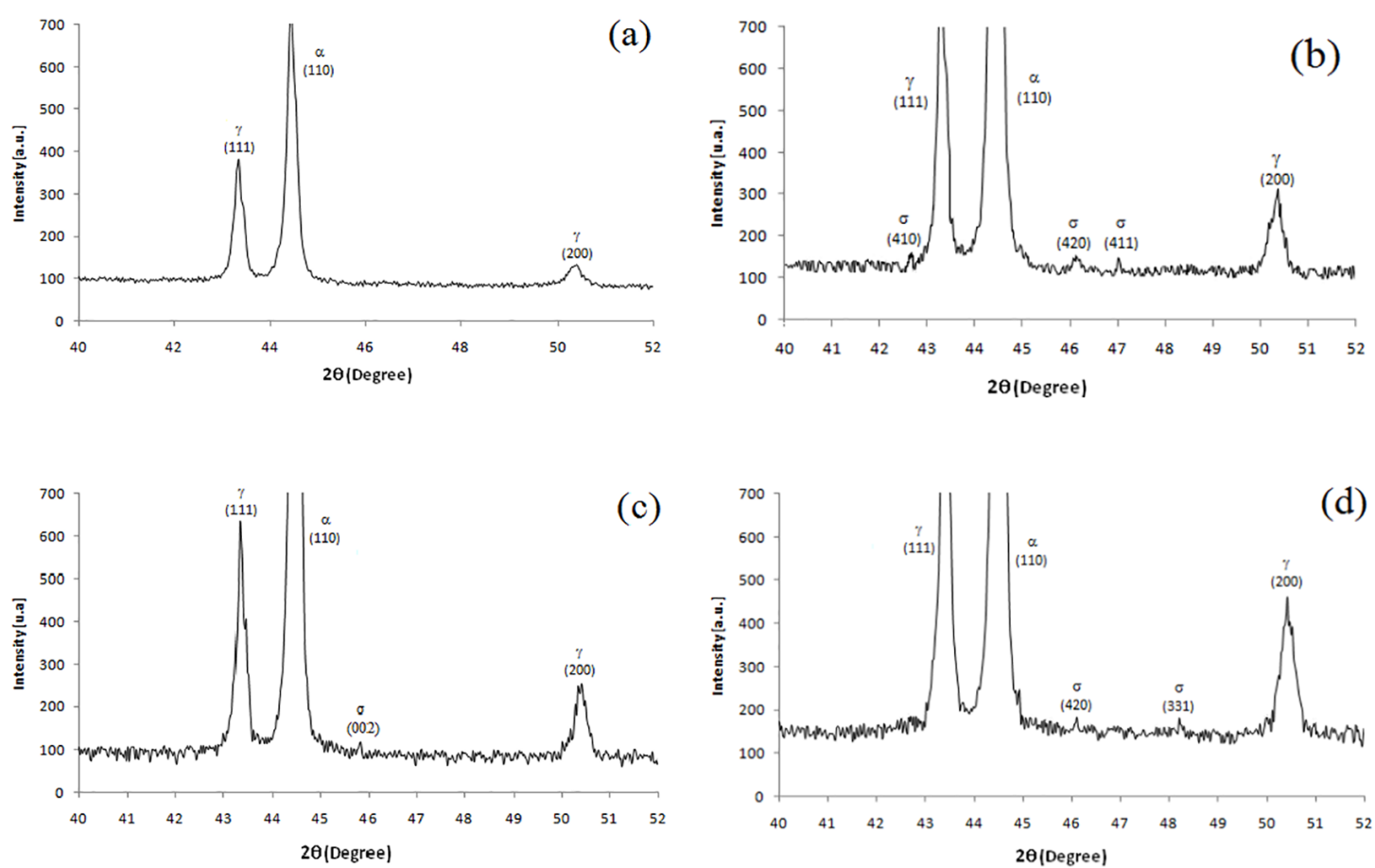

Figure 2. XRD patterns of the sample. (a) as-received; (b) solution-treated at $1150^{\circ} \mathrm{C}$; (c) solution-treated at $1150^{\circ} \mathrm{C}$ and aged at $850^{\circ} \mathrm{C}$ for $5 \mathrm{~min}$., (d) solution-treated at $1150^{\circ} \mathrm{C}$ and aged at $850^{\circ} \mathrm{C}$ for $10 \mathrm{~min}$

Table 2. Microhardness values of UNS S32520 SDSS

\begin{tabular}{cc}
\hline Condition & $\begin{array}{c}\text { Microhardness } \\
\text { (HV) }\end{array}$ \\
\hline As-received & 281 \\
Solution-treated at $1150^{\circ} \mathrm{C}$ & 292 \\
Solution treated at $1150^{\circ} \mathrm{C}-$ aged for $5 \mathrm{~min}$ & 282 \\
Solution-treated at $1150^{\circ} \mathrm{C}-$ aged for $10 \mathrm{~min}$ & 284 \\
\hline
\end{tabular}

Table 3. Open circuit potential of UNS S32520 SDSS in $3.5 \%$ $\mathrm{NaCl}$ solution at $25^{\circ} \mathrm{C}$

\begin{tabular}{cc}
\hline Condition & E (V/SCE) \\
\hline As-received & -0.2582 \\
Solution-treated at $1150^{\circ} \mathrm{C}$ & -0.2585 \\
Solution treated at $1150^{\circ} \mathrm{C}-$ aged for $5 \mathrm{~min}$ & -0.2093 \\
Solution-treated at $1150^{\circ} \mathrm{C}-$ aged for $10 \mathrm{~min}$ & -0.2700 \\
\hline
\end{tabular}

In the study of SDSS, it is worthwhile to know the PREN (pitting resistance equivalent number) values of each phase. The Table 5 shows the chemical composition of the main elements for the studied conditions obtained by EDS. It can be observed from that a preferential selective corrosion of one of the phases may occur due to the significant difference of the PREN values between the phases.

Similar PREN values between the phases indicate that the elements responsible for pitting resistance $(\mathrm{Cr}$ and $\mathrm{Mo})$ are

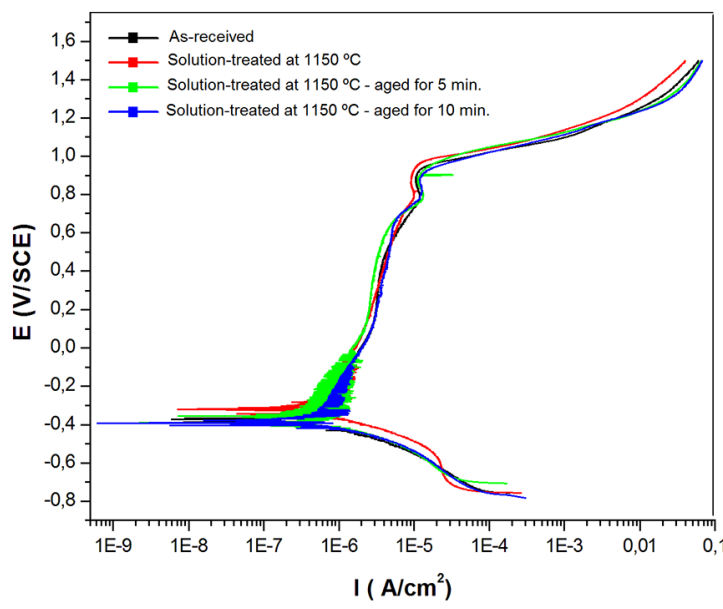

Figure 3. Potentiodynamic polarization curves of UNS S32520 SDSS in the following conditions: as-received, solution-treated at $1150^{\circ} \mathrm{C}$, solution-treated at $1150^{\circ} \mathrm{C}$ and aged at $850^{\circ} \mathrm{C}$ for 5 and 10 minutes. $3.5 \% \mathrm{NaCl}$ solution

evenly distributed. Therefore, the passive film formed over the metallic surface will present a very uniform composition, avoiding composition defects in the passive film. According to the values of the chemical composition shown in Table 1, the overall PREN value calculated for the SDSS is 41.7.

It is worthwhile mentioning that the pits, after nucleated at the interfaces, grow into the ferrite, although ferrite has a PREN greater than the austenite. This is because $\mathrm{Cr}$ and $\mathrm{Mo}$ 
Table 4. Electrochemical parameters of UNS S32520 SDSS obtained in $3.5 \% \mathrm{NaCl}$ solution at $25^{\circ} \mathrm{C}$

\begin{tabular}{ccccc}
\hline Condition & $\mathbf{E}_{\text {corr }}(\mathbf{V} / \mathbf{S C E})$ & $\mathbf{I}_{\text {corr }}\left(\mathbf{A} / \mathbf{c m}^{2}\right)$ & $\mathbf{E}_{\text {pit }}(\mathbf{V} / \mathbf{S C E})$ & $\mathbf{I}_{\text {pass }}\left(\mathbf{A} / \mathbf{c m}^{2}\right)$ \\
\hline As-received & -0.379 & $5.514 \times 10^{-7}$ & 0.914 & $3.266 \times 10^{-6}$ \\
Solution-treated at $1150^{\circ} \mathrm{C}$ & -0.333 & $9.075 \times 10^{-7}$ & 0.916 & $3.249 \times 10^{-6}$ \\
Solution-treated at $1150^{\circ} \mathrm{C}$ - aged for $5 \mathrm{~min}$ & -0.400 & $1.210 \times 10^{-7}$ & 0.912 & $2.796 \times 10^{-6}$ \\
Solution-treated at $1150^{\circ} \mathrm{C}$ - aged for $10 \mathrm{~min}$ & -0.381 & $9.550 \times 10^{-7}$ & 0.914 & $3,664 \times 10^{-6}$ \\
\hline
\end{tabular}

Table 5. Pitting resistance equivalent number (PREN) of ferrite and austenite phases

\begin{tabular}{|c|c|c|c|c|c|c|}
\hline Condition & & Phase & $\mathrm{Cr}$ & Mo & $\mathbf{N}$ & PREN \\
\hline \multirow[t]{2}{*}{ As -received } & & $\alpha$ & 28.4 & 5.3 & 0.2 & 49.5 \\
\hline & & $\gamma$ & 25.6 & 3.9 & 0.2 & 41.9 \\
\hline \multirow[t]{2}{*}{ Solution-treated at $1150^{\circ} \mathrm{C}$} & & $\alpha$ & 24.9 & 3.1 & 0.2 & 38.5 \\
\hline & & $\gamma$ & 24.2 & 2.2 & 0.2 & 34.8 \\
\hline \multirow[t]{2}{*}{ Solution-treated at $1150^{\circ} \mathrm{C}$ - aged for $5 \mathrm{~min}$} & $\alpha$ & 28.1 & 4.2 & 0.2 & \multicolumn{2}{|c|}{45.6} \\
\hline & $\gamma$ & 25.5 & 3.7 & 0.2 & \multicolumn{2}{|c|}{41.3} \\
\hline \multirow[t]{2}{*}{ Solution-treated at $1150^{\circ} \mathrm{C}$ - aged for $10 \mathrm{~min}$} & $\alpha$ & 24.5 & 4.8 & 0.2 & \multicolumn{2}{|c|}{43.9} \\
\hline & $\gamma$ & 23.6 & 3.4 & 0.2 & \multicolumn{2}{|c|}{38.5} \\
\hline
\end{tabular}

act as stabilizer and passivating elements of ferrite, while in the austenite, they act only as passivating elements. The effect of these elements in improving the pitting resistance is much higher in austenite than in ferrite. Ferrite needs a much greater amount of these elements than austenite, so that it has the same pitting resistance.

EIS results are shown in Figures 4 and 5 as Nyquist and Bode phase angle diagrams, respectively, for the conditions studied. As can be seen from the Figures, the Nyquist diagrams present semicircles and the Bode diagram reveals high phases angles over a large frequency range and a linear relationship with inclination close to -1 , between $\log |\mathrm{Z}|$ and $\log (\mathrm{f})$ and phase angle close to $-80^{\circ}$, in the low frequency region, for all the tested samples, which reveals a highly capacitive behavior, typical of passive materials. In fact, the passive behavior of SDSS is due to the very low proportion of sigma face at the surface, comparatively of proportion of passive area ${ }^{4}$.

The equivalent circuit in Figure 6 is proposed for fitting EIS data to quantify the electrochemical parameters. In this equivalent circuit, Rs represents solution resistance; CPE (constant phase element) is double charge layer capacitance (C); $\mathrm{Rp}$ (polarization resistance) is the charge-transfer resistance. The electrochemical impedance parameters obtained from the fitting of EIS diagrams are shown in Table 6.

According to the results, there was no alteration in Rs in the studied conditions. The solution-treated condition at $1150^{\circ} \mathrm{C}$ and the aged at $850^{\circ} \mathrm{C}$ for 5 min present higher polarization resistance; therefore, it is the highest corrosion resistant condition. This fact can be verified by the values of Icorr $1.210 \times 10^{-7}$ A.cm ${ }^{-2}$ and Ipass of $2.796 \times 10^{-6}$ A.cm ${ }^{-2}$, both with lower values than for the other conditions, as presented in Table 4.

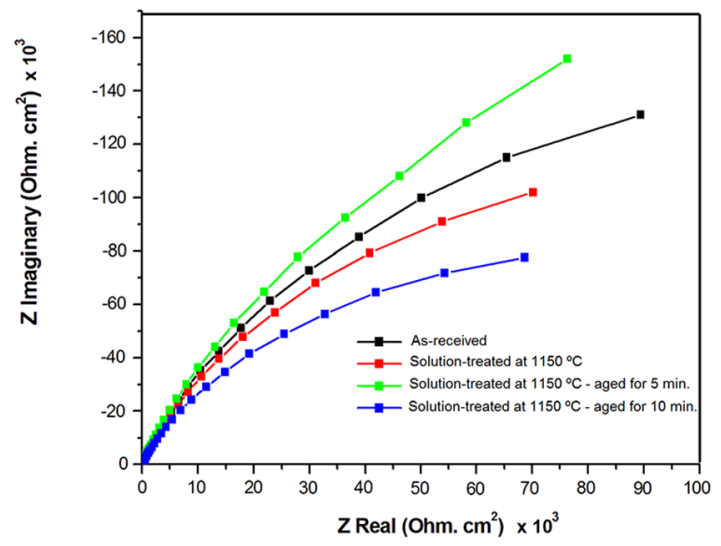

Figure 4. Nyquist Diagram of UNS S32520 super duplex stainless steel in the conditions: as-received, solution-treated at $1150^{\circ} \mathrm{C}$, solution treated at $1150^{\circ} \mathrm{C}$ and aged at $850^{\circ} \mathrm{C}$ for 5 and $10 \mathrm{~min}$. in $3.5 \% \mathrm{NaCl}$ solution at room temperature

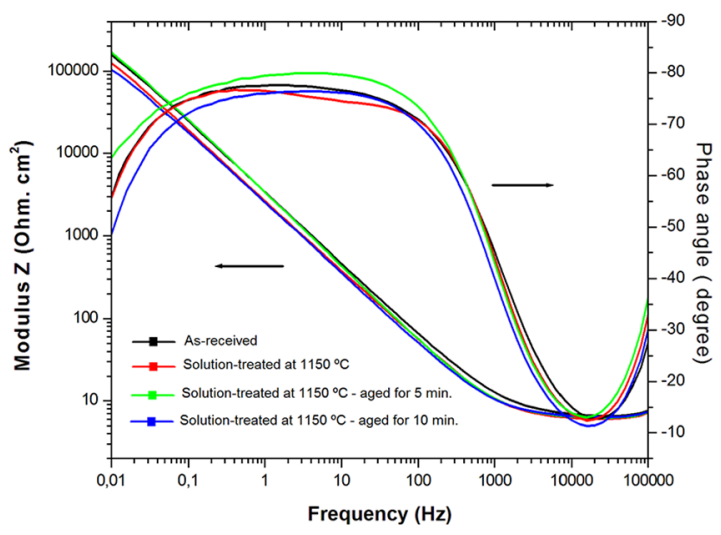

Figure 5. Bode phase angle diagrams of UNS S32520 super duplex stainless steel in the conditions: as-received, solution-treated at $1150^{\circ} \mathrm{C}$, solution-treated at $1150^{\circ} \mathrm{C}$ and aged at $850^{\circ} \mathrm{C}$ for 5 and 10 minutes in a $3.5 \% \mathrm{NaCl}$ solution at room temperature 
Table 6. Values of resistance and constant phase element obtained for the UNS S32550 SDSS

\begin{tabular}{|c|c|c|c|c|}
\hline \multirow{2}{*}{ Condition } & \multirow{2}{*}{ Rs Ohm.cm² } & \multicolumn{2}{|c|}{ CPE } & \multirow{2}{*}{ Rp Ohm.cm ${ }^{2}$} \\
\hline & & $\mathrm{C}\left(\mathrm{F} . \mathrm{cm}^{-2}\right)$ & (n) & \\
\hline As-received & 6.72 & $6.08 \times 10^{-5}$ & 0.86 & 455210 \\
\hline Solutio-treated at $1150^{\circ} \mathrm{C}$ & 6.10 & $7.77 \times 10^{-5}$ & 0.85 & 372240 \\
\hline Solution-treated at $1150^{\circ} \mathrm{C}$ - aged for $5 \mathrm{~min}$ & 6.40 & $6.01 \times 10^{-5}$ & 0.88 & 522230 \\
\hline Solution-treated at $150^{\circ} \mathrm{C}$ - aged for $10 \mathrm{~min}$ & 6.48 & $8.23 \times 10^{-5}$ & 0.85 & 214680 \\
\hline
\end{tabular}

Rs: solution resistance; Rp: polarization resistance; $\mathrm{C}$ : capacitance; $\mathrm{n}$ : factor.

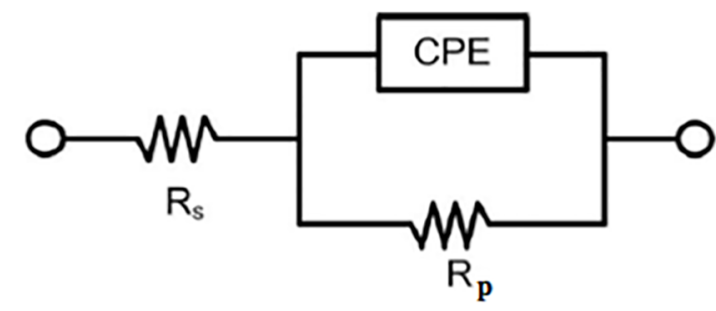

Figure 6. Electrical equivalent circuit used to fit the Bode phase diagrams

The solution-treated condition at $1150^{\circ} \mathrm{C}$ and aged at $850^{\circ} \mathrm{C}$ for $10 \mathrm{~min}$ is less resistant to corrosion. This behavior is due to the presence of secondary phases, specially the sigma phase, provoking impoverishment of $\mathrm{Cr}$ and $\mathrm{Mo}$ in the ferritic matrix ${ }^{17,18}$. The Rp values for all the conditions are very close to the values found by Yoo et al. ${ }^{15}$, indicating the existence of a passive film.

The solution-treated condition at $1150^{\circ} \mathrm{C}$ and aged at $850^{\circ} \mathrm{C}$ for $5 \mathrm{~min}$ presented a factor $\mathrm{n}$ value very close to 0.89 , which indicates the formation of a homogeneous passive film over the metal surface ${ }^{15,16}$. This behavior is due to the variations on the distribution of the elements in the microstructure during the manufacturing process and subsequent heat treatments. The elements may be homogeneously distributed forming a single phase or partitioned in the microstructure, thus, the homogeneity of the oxide film formed over the metallic surface depends on the distribution of the alloy elements and the on volumetric fraction of each phase. A non-uniform element distribution will probably favor the formation of a heterogeneous film, with different properties at different points.

In the other conditions of this study the factor $n$ values are slightly below the 0.89 , probably due to the fact that it does not present the same uniformity in the passive film of this condition.

\section{Conclusions}

The treatment of aging favored the precipitation of secondary phases, mainly the sigma phase. The microhardness of the SDSS, is not affected by the presence of the sigma phase during the aging heat treatments.
The polarization curves present two passive regions, one is associated with the passivation of the ferrite phase and other is associated with the austenite phase. Small oscillations in current density resulting from the nucleation and repassivation of metastable pits, which grow and repassivate in a few seconds, caused variations in current density, which accumulated during the corrosion process. The small variation in the potentiodynamic polarization and in the electrochemical impedance results is due to the non-uniform distribution of the chemical elements, which favors the formation of a heterogeneous film with different properties at different points.

Concerning to the influence of the microstructure in the electrochemical behavior of the SDSS, it is possible infer that the best corrosion resistance of the sample in the solution-treated at $1150^{\circ} \mathrm{C}$ and aged at $850^{\circ} \mathrm{C}$ for $5 \mathrm{~min}$ condition is due to the significant dissolution of sigma phase and a more favorable partition of the elements $\mathrm{Cr}$ and Mo in the microstructure. However, when the aging time is increased for $10 \mathrm{~min}$, it occurs the re-precipitation of a considerable amount of sigma phase, leading to the embrittlement of the austenite-ferrite boundary and a lower corrosion resistance due to a non-uniform elements distribution. Thus, this study indicates that thermal processing of SDSS in short periods of exposition in high temperatures (less than $10 \mathrm{~min}$ ) does not reduce its corrosion resistance.

\section{Acknowledgements}

The authors acknowledge the Brazilian agencies CAPES, CNPq and FAPEMIG for the financial support.

\section{References}

1. Herrera C, de Lima NB, Kliauga AM, Padilha AF. Microstructure and texture of duplex stainless steel after melt-spinning processing. Materials Characterization. 2008;59(1):79-83.

2. Li J, Ma Z, Xiao X, Zhao J, Jiang L. On the behavior of nitrogen in a low-Ni high-Mn super duplex stainless steel. Materials \& Design. 2011;32(4):2199-2205.

3. Tavares SSM, de Noronha RF, da Silva MR, Neto JM, Pairis S. $475^{\circ} \mathrm{C}$ embrittlement in a duplex stainless steel UNS S31803. Materials Research. 2001;4(4):237-240. 
4. Fontes TF, Magnabosco R, Terada M, Padilha AF, Costa I. Corrosion Versus Mechanical Tests for Indirect Detection of Alpha Prime Phase in UNS S32520 Super Duplex Stainless Steel. Corrosion. 2011;67(4):045004-1-045004-7.

5. Kiahosseini SR, Baygi SJM, Khalaj G, Khoshakhlagh A, Samadipour R. A Study on Structural, Corrosion, and Sensitization Behavior of Ultrafine and Coarse Grain 316 Stainless Steel Processed by Multiaxial Forging and Heat Treatment. Journal of Materials Engineering and Performance. 2018;27(1):271-281.

6. Chinizadeh M, Kiahosseini SR. Deformation, microstructure, hardness, and pitting corrosion of 316 stainless steel after laser forming: A comparison between natural and forced cooling. Journal of Materials Research. 2017;32(16):3046-3054.

7. Paulraj P, Garg R. Effect of intermetallic phases on corrosion behavior and mechanical properties of duplex stainless steel and super-duplex stainless steel. Advances in Science and Technology Research Journal. 2015;9(27):87-105.

8. Pardal JM, Tavares SSM, Fonseca MC, de Souza JA, Côrte RRA, de Abreu HFG. Influence of the grain size on deleterious phase precipitation in superduplex stainless steel UNS S32750. Materials Characterization. 2009;60(3):165-172.

9. Silva R, Baroni LFS, Silva MBR, Afonso CRM, Kuri SE, Rovere CAD. Effect of thermal aging at $475^{\circ} \mathrm{C}$ on the properties of lean duplex stainless steel 2101. Materials Characterization. 2016;114:211-217.

10. Gholami M, Hoseinpoor M, Moayed MH. A statistical study on the effect of annealing temperature on pitting corrosion resistance of 2205 duplex stainless steel. Corrosion Science. 2015;94:156-164.
11. Pohl M, Storz O, Glogowski T. Effect of intermetallic precipitations on the properties of duplex stainless steel. Materials Characterization. 2007;58(1):65-71.

12. Brytan Z, Niagaj J. The lean duplex stainless steel welded joint after isothermal aging treatment. Archives of Materials Science and Engineering. 2013;60(1):24-31.

13. Padilha AF, Plaut RL. Phase Transformation and Microstructure. In: Alvarez-Armas I, Degallaix-Moreuil S, eds. Duplex Stainless Steels. London: Wiley-ISTE; 2009.

14. Martins M, Casteletti LC, Hara PLT. Caracterização microestrutural e comportamento à corrosão do aço inox super duplex ASTM A890 GR 6A. In: $59^{\circ}$ Congresso Anual da ABM; $2004 \mathrm{Jul}$ 19-22; São Paulo, SP, Brazil.

15. Yoo YH, Choi YS, Kim JG, Park YS. Effects of Ce, La and $\mathrm{Ba}$ addition on the electrochemical behavior of super duplex stainless steels. Corrosion Science. 2010;52(4):1123-1129.

16. Kim ST, Jang SH, Lee IS, Park YS. Effects of solution heat-treatment and nitrogen in shielding gas on the resistance to pitting corrosion of hyper duplex stainless steel welds. Corrosion Science. 2011;53(5):1939-1947.

17. Escriba DM, Materna-Morris E, Plaut RL, Padilha AF. Chi-phase precipitation in a duplex stainless steel. Materials Characterization. 2009;60(11):1214-1219.

18. Nilson JO. Super duplex stainless steels. Materials Science and Technology. 1992;8(8):685-700. 